\title{
FACTORS AFFECTING THE INCREASING COSTS OF AMS CONFERENCES
}

\author{
by David M. Schultz, Keith Seitter, Lance Bosart, Claudia Gorski, and Celeste lovinella
}

M eetings at the American Meteorological Society (AMS) cost $\$ 2.73$ million per year (averaged over the two-year cycle of 2004 and 2005), accounting for $19.6 \%$ of the Society's annual budget. Typically over a two-year cycle, the AMS holds 22 specialty conferences in 12 locations, plus two annual meetings, each of which includes an average of 25 conferences and symposia. Approximately seven full-time employees are dedicated to meetings (working with a number of other AMS staff members as needed), in support of the many volunteers who give generously of their time to organize the various conferences and symposia. It is a complex operation, especially the annual meetings, where many concurrent sessions must be coordinated to allow useful interactions among attendees from various specialties.

AMS members may have noticed that the cost of attending conferences has increased dramatically in recent years. Ten years ago, the total cost of traveling to, attending, and presenting at an AMS-sponsored conference was typically $\$ 1,000$. Now, this cost approaches $\$ 2,000$. The AMS is not the only professional society facing this challenge-the Society for Industrial and Applied Mathematics (SIAM) has also discussed the costs of meetings with their member-

AFFILIATIONS: SCHULTZ*-Cooperative Institute for Mesoscale Meteorological Studies, University of Oklahoma, and NOAA/ National Severe Storms Laboratory, Norman, Oklahoma; SEITTER AND GORSKI-American Meteorological Society, Boston, Massachusetts; BOSART AND lOVINELLA-Department of Earth and Atmospheric Sciences, State University of New York, University at Albany, Albany, New York

*CURRENT AFFILIATION: Finnish Meteorological Institute, and University of Helsinki, Helsinki, Finland

CORRESPONDING AUTHOR: Dr. David M. Schultz, NOAA/National Severe Storms Laboratory/FRDD, Suite 4356, 120 David L. Boren Blvd., Norman, OK 73072-7326

E-mail: david.schultz@noaa.gov

DOI:10.1175/BAMS-88-3-408

@2007 American Meteorological Society ship (see "For Further Reading" at the end of this paper). Only 10 years ago, the average annual budget for meetings at the AMS was $\$ 1.4$ million, about half of what it is now.

In this paper, we explore the rising costs of attending and presenting papers at AMS conferences since 1971, showing an increase several times that of inflation. We discuss the major expenses (hotel, airfare, registration, and authorship fees), provide a sample budget for a specialty conference, and explore how future AMS conferences can be made more affordable.

HOTEL. A five-night hotel stay is typically $50 \%-$ $70 \%$ of the total cost of attending a conference, before taxes. Where the government rate is available, attendees can save anywhere from $\$ 2$ to $\$ 35$ per night off AMS-negotiated room rates. Some hotels charge fees on top of the nightly room rate (see sidebar; these, as well as local and state taxes, are all excluded from our calculations).

The cost of a five-night stay in the conference hotel at the Hurricanes and Tropical Meteorology Conference and the AMS Annual Meeting shows an increase of roughly a factor of 10 from 1971 to 2006, with a doubling of the cost in the last 10 years (Fig. 1). Why hotel rates have increased so much has been difficult to understand. A Web search for information indicated that rising labor and energy costs have played a role ( $w w w$.hotel-online.com/ Neo/News/PR200I_2nd/June0I_CanadianReview. html; www.fhrai.com/Mag-News/magGloballndustry.asp). Perhaps more significantly, hotel owners, realizing the profitability of conferences, have built many new hotels, passing on construction costs to their guests. In addition, some hotels have decided to keep rates high, even in the face of reduced occupancy and poor financial times (www.forbes. com/2002/05/30/0530feat.html). This strategy has paid off for the industry, as the stock prices of hotel chains have risen 3-4 times over the last five years, an increase much larger than most financial indicators. In any case, the rising hotel rates are clearly a 
problem for other societies as well (e.g., SIAM) and represent one of the big challenges in reining in the rising costs of conferences.

AIRFARE. Since 1995, the Bureau of Transportation Statistics has computed the Air Travel Price Index (ATPI), which "is based on actual fares paid by travelers, not published fares." Prices have fluctuated by only about $20 \%$ during the last 11 years (Fig. 2). During this time, airfares have typically ranged between $\$ 200$ and $\$ 400$ for economy-class, nonrefundable (restricted) tickets. Federal government travel costs are usually higher, but are unrestricted fares (meaning changes to the itinerary can be made without additional cost). Subsequent to the first quarter of 2006, airfares have continued to rise according to the index in Fig. 2 (not shown), partly because the price of oil remains relatively high and partly because demand for fewer available seats is continuing to increase.

REGISTRATION FEE. Registration at the AMS Annual Meeting cost $\$ 15$ for AMS members in 1971, but has risen to $\$ 360$ in 2006 for early registration (Fig. 3), a 24-fold increase. Except for a doubling of the registration fee between 1985 and 1987, these costs rose $\$ 5-\$ 10$ a year before 1998 . The rapid increase in registration fees in the mid-1980s was apparently due to changes in the budget philosophy during that period to have the meeting registration fees cover a greater proportion of Society expenses. After 1998, the base registration fee rose fairly uniformly at $\$ 15$ per year, but the fee for a specific conference series changed less uniformly because each program committee could include special events that sometimes added as much as $\$ 25$ to the registration fee. The base fee for the specialty meetings is set to roughly that of the Annual Meeting, which has been increasing by $\$ 15$ a year with two exceptions. It increased by $\$ 40$ in 2002 when the Poster Session Luncheon ticket was included in the registration fee. In 2003, the registration fee increased $\$ 20$ when the AMS adopted a formal poster session each day with food. ${ }^{1}$

\footnotetext{
${ }^{1}$ The Annual Meeting poster sessions have been working well since the introduction of a formal time each day, with all conferences standing down during that period, and food being part of the poster session. Although adding to the cost of the Annual Meeting, most attendees seem to feel the AMS has now gotten the poster sessions right after years of not serving the poster authors very well.
}

The more rapid increase in registration fees since 1998 was due in large part to several factors. One was the introduction of more technology into meetings, in part to accommodate electronic presentations and more online functionality (e.g., online registration, online tools for creating the meeting program). But the electronic era has also resulted in some additional expenses. Here is a list of some of the charges that the AMS paid for just one meeting room at the weeklong 2006 Hurricanes and Tropical Conference: screen-\$1,125; Lavaliere microphone-\$225 (a wireless microphone would have been $\$ 700$ ); house sound- $\$ 1,500$; computer $-\$ 275$. The computer projectors ( $\$ 4,000-\$ 5,000$ each to purchase) are usu-

\section{THE 2006 HURRICANES AND TROPICAL METEOROLOGY CONFERENCE}

In terms of costs, the 2006 Hurricanes and Tropical Meteorology Conference represents a special case, although illustrating some aspects of how the AMS plans meetings and arrives at their costs. This conference was originally scheduled to be held in downtown New Orleans, but, in the aftermath of Hurricane Katrina, that was not possible. The AMS staff and the program committee were able to secure a new venue in Monterey, California, on short notice. Limited by time and availability, the AMS had little negotiating room. This led to higher hotel costs than would have been the case if the meeting had been in New Orleans as planned, including the mandatory hotel resort fee of $\$ 10$ a day. Hotels frequently charge this resort fee as part of the initial contract they send to the AMS, and in most cases where several meeting locations are being considered, the AMS can almost always have that fee removed from the contract. The resort fee included free bottled water in each room, free 800 calling, and $\$ 5$ off the cash-andcarry lunch each day for those who chose that lunch option, although most attendees would agree those items were not worth $\$ 10$ a day.

Another factor increasing the registration fee was that the program committee made a decision to have the conference banquet served buffet style at the Monterey Aquarium followed by a two-hour self-guided tour, knowing that this would increase the registration fee by an additional $\$ 40$ per person beyond the normal base level. Program committees have been given such options in recent years so that the meetings can offer unique and worthwhile experiences for the attendees. Not all program committees exercise options that increase the registration fee, but when they do, it is with full understanding of the impact on the conference budget and the increased registration fee that attendees will face. 


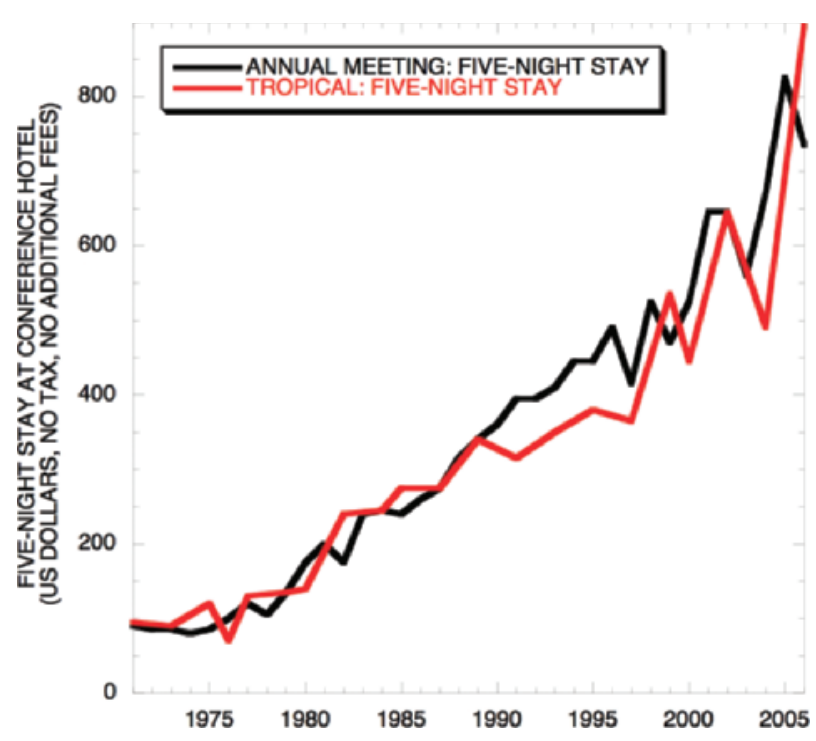

FIG. I. Five-night stay at the conference hotel for the AMS Annual Meeting and Hurricane and Tropical Conferences, 1971-2006. No taxes or additional fees are included.

ally supplied by the AMS for specialty conferences, although shipping usually takes its toll on the equipment. Rentals would have been $\$ 1,750$. The timer is supplied by the AMS for specialty meetings, but at the Annual Meeting is rented for $\$ 125$. Other fees include renting the computers for e-mail stations ( $\$ 825$ for the week) and Internet connectivity for e-mail and the registration desk ( $\$ 3,125$ for the week). All of these expenses are folded into the registration fee.

The AMS began increasing the registration fees to offset these expenses, figuring that a few years of modest increases would suffice. After the collapse of the technology bubble in March 2000, attendance decreased (look ahead to Fig. 5a), in part, as a weaker national economy constricted travel budgets. In addition, after a perceived unsuccessful Annual Meeting in January 1999, the report from the AMS Ad Hoc Committee on Meetings (www.ametsoc.org/EXEC/ TenYear/roger.w_finalreport.html) was accepted by the Council in October 1999, leading to major changes in the Annual Meeting structure. Starting in 2001, the Annual Meeting featured a central theme with fewer conferences and symposia, fewer concurrent sessions, and more coordination within the program to encourage interdisciplinary interactions. This restructuring reduced the number of calls for papers to which authors could respond, and the new interdisciplinary symposia were slow to attract audiences. The result was several years of significantly smaller annual meetings. With fewer attendees, the meeting costs could only be supported by fee increases, resulting in a positive feedback where increasing the registration fee each year was not enough to offset costs. (In fact, the AMS lost money on meetings for several years, but still tried to keep the increases as small as possible because of the concern attendees had expressed about increases in the registration fees in recent years.) Finally, in 2005, the AMS posted a nearly balanced budget for meetings.

The registration fee for student members has also increased. In 1971, registration was $\$ 2$ for local undergraduate students. (Graduate students and nonlocal undergraduates presumably paid the member rate until 1979, when the definition of "students" apparently became unrestricted.) By 2006 , early registration cost $\$ 150$ for an AMS student member. Unlike the member registration fees, however, the rise in the student registration fee has not been monotonic. In 1995, the AMS honored its 75th anniversary by reducing the student fee from $\$ 110$ to $\$ 95$ (see the October 1994 Bulletin, p. 1945). The fee decreased to $\$ 85$ in 1996 before rising again in 1997.

The change in registration fees at meetings is also a measure of how the AMS Annual Meetings have changed over time. Over the past few years, 2,600-2,700 paid registrants, not including the exhibitor staff, have attended the Annual Meeting, giving over 1,600 presentations at over 20 conferences and symposia. In 2000, there were 2,300 attendees giving 1,395 presentations at 16 conferences and symposia. In 1990, there were 254 presentations at 7 conferences and symposia (attendance numbers for this and earlier meetings were not available, although the meetings in the 1970s and 1980s reportedly only had a few hundred attendees). In 1980, there were no specific conferences, but there were six scientific sessions over three days with 26 presentations, plus a few panel discussions. In 1971, there were no specific conferences, but 53 presentations in the first three days, then 10 presentations during a day of joint sessions with another society. Thus, the character of the Annual Meeting has changed pretty dramatically over the last 35 years. Furthermore, these changes in character occurred during a period with only modest growth in AMS membership (8,780 in 1971; 9,758 in $1980 ; 10,550$ in $1990 ; 11,602$ in 2000 ; and 11,719 in 2005), indicating that the large changes in attendance at AMS Annual Meetings is principally due to the changes in the meeting structure rather 
than the growth in AMS membership. Finally, the larger size of the AMS Annual Meeting means that the venues that can host a meeting of this scale are limited, and convention centers capable of handling 2,500-3,000 people charge much more for their facilities than a small hotel with meeting facilities for 150-300 people.

\section{PREPRINT CHARGES AND ABSTRACT}

FEES. The AMS also charges fees for publishing a preprint volume or a CD-ROM with Web-hosting of preprints and oral presentations. Since 2002, all meeting program chairs have chosen the electronic format for dissemination of preprints. When hardcopy preprint volumes were published, authors were assessed a page charge. This fee covered the actual printing costs as well as a portion of the staff costs for the meeting. Much of the staff activity associated with preparing the program overlapped with preparation of the preprint, so the author charges helped lower registration fees. Since 2002, however, hardcopy volumes have been phased out. Several options have been made available to conference presenters depending on what levels of dissemination a particular conference offers (a decision of the conference program committee) and what the author chooses.

In 2001, a $\$ 60$ abstract submission fee was instituted for all conference presentations; it was raised to $\$ 70$ in 2006 . This fee was instituted "in response to the suggestions of the program committees" (see the July 2000 Bulletin, p. 1612) because there was a feeling that having an author invest in the meeting up front would lead to a greater commitment later, with fewer "no shows" and a stronger meeting overall. Interestingly, the percentage of withdrawn papers at the Annual Meeting has not decreased with the introduction of the abstract fee (3\% and 5\% in 1999 and 2000 before introduction of the fee, and $8 \%, 5 \%$, $5 \%, 3 \%, 3 \%$, and $4 \%$ for $2001-06$ after the fee). The abstract submission fee "not only helps to cover the costs associated with processing the abstracts and generating the program (which had previously been partially subsidized from the preprint page charge fees), but it also provides for the next step in utilizing the Web for AMS meetings-the acceptance of the complete preprint paper in electronic form" (see the July 2000 Bulletin, p. 1612).

As early as 1982, the fee for a 1-2-page preprint was $\$ 50$. By 1998 , it had risen to $\$ 95$, possibly in one or two steps (the yearly values could not be tracked down from the AMS archives). When the abstract fee was implemented in 2001, the preprint fee dropped to $\$ 65$, but in 2005 had risen to $\$ 130$ for preprints published in a CD-ROM online database, with the presentation also recorded and made available online after the meeting (authors can choose a subset of these options for a lower fee). It is worth noting that this fee now provides for a paper of many pages, rather than just $1-2$, and allows unlimited use of color figures with no additional charge (inserting a color figure in the hardcopy preprint volume was an additional $\$ 1,500$ per page for authors). Geerts et al. (2006, their Fig. 2) showed that the percentage of preprints included in the CD-ROM has decreased since the published preprint volume has been phased out. Thus, income from preprint fees will also likely decrease in the

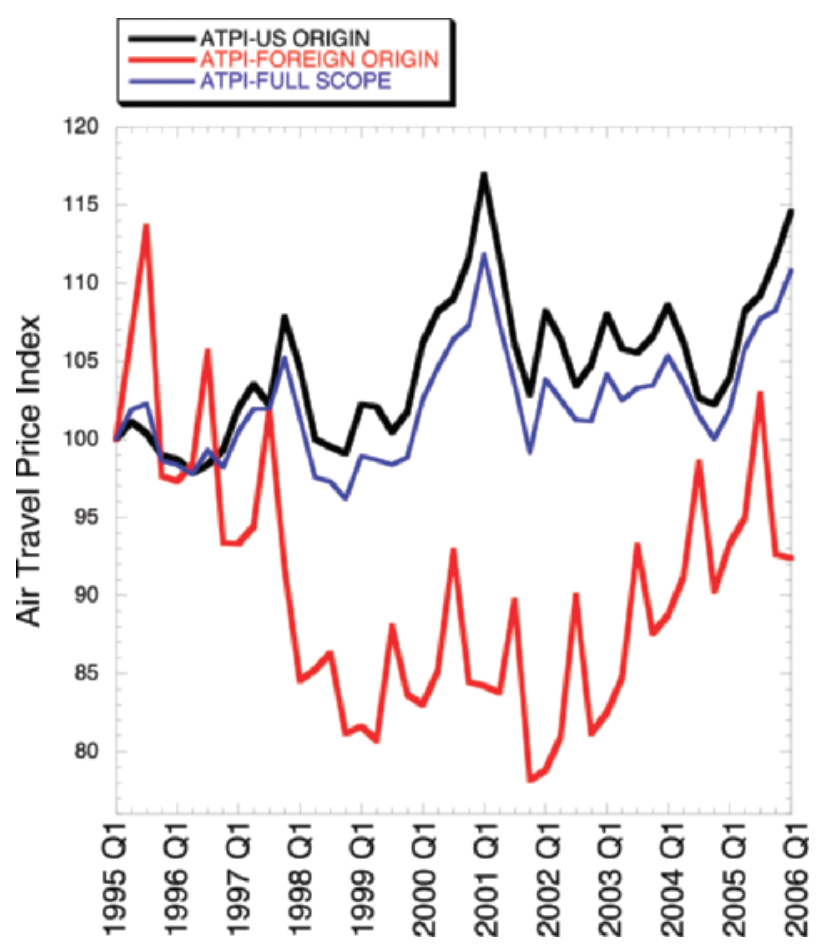

FIg. 2. Air Travel Price Index (ATPI) for first financial quarter (QI; Jan-Mar) 1995 to QI 2006. For definition of ATPI, see www.bts.gov/xml/atpi/src/index.xml. The U.S.-Origin ATPI curve reflects the cost of itineraries originating in the United States, regardless of whether the destinations are domestic or international, the Foreign-Origin ATPI curve reflects the cost of itineraries originating in a foreign country with a destination in the United States, and the Full-Scope ATPI combines these two itineraries. An annual cycle exists with prices in the fourth quarter being higher than those during the rest of the year. [Data from the Bureau of Transportation Statistics Web page (www.bts.gov/xml/atpi/src/datadisp_table.xml).] 


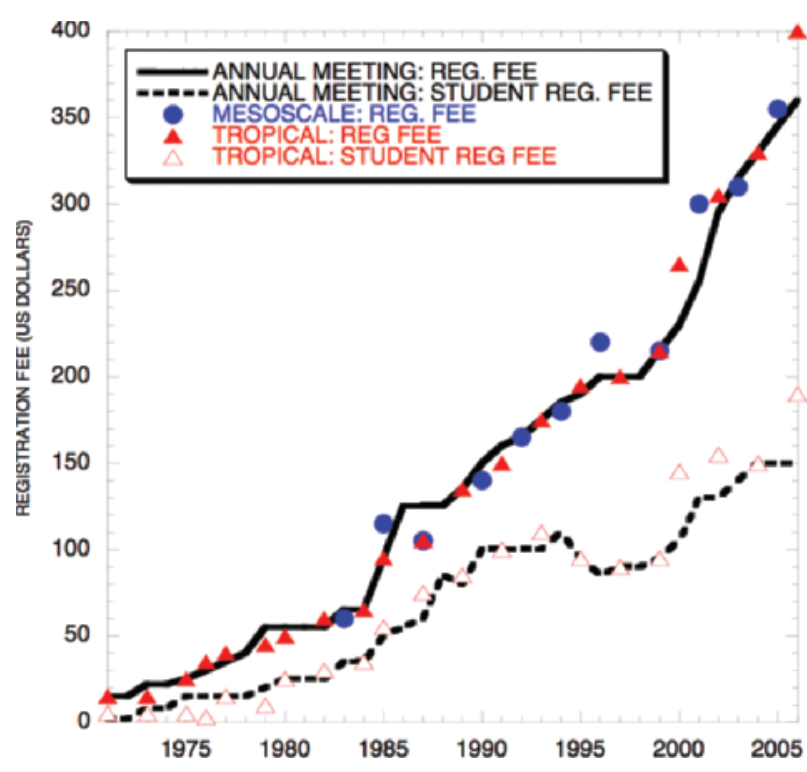

FIG. 3. Registration fees for AMS Members (early registration rates, when available) and student members of the AMS for the AMS Annual Meeting, Mesoscale Processes Conferences, and Hurricane and Tropical Meteorology Conferences from I97I to 2006. During 2000-02, the AMS offered a $\$ 20$ discount for registering for a meeting online. In 2003, this discount was $\$ 10$. By 2004, there was no discount. This discount, when offered, was not factored into any of our calculations.

future. Currently, each conference program committee decides whether to have a preprint volume, CD-ROM, or neither (only online hosting). These services (contracted with The Conference Exchange; www.confex.com) cost the AMS $\$ 50$ per attendee (see Table 1).

OTHER. Other expenses include costs of transportation from the airport to the hotel and vice versa, ranging from $\$ 10$ to $\$ 30$ each way, if by taxi or shuttle service. Some attendees prefer to rent a car, which, in addition to the rental fee, may also entail parking costs as much as $\$ 25$ a day at some hotels. State and local taxes on hotel stays can easily add $15 \%-20 \%$ to the cost of the hotel bill. Per diem and internet fees also vary. None of these expenses is included in the total costs of attending conferences that follow, yet they could add several hundred more dollars to the cost of attending meetings.

TOTAL COSTS. Taking these values above, we can calculate the total cost of attending the AMS Annual Meeting (Fig. 4), assuming a five-night stay in the conference hotel and one paper (other exclusions and assumptions are detailed in Fig. 4). From 1971 to 2006 , the total cost has increased from around $\$ 100$ to over $\$ 1,300$ (not including airfare and per diem), or a factor of roughly 13. Unaccounted-for expenses (travel/airfare, per diem, hotel taxes) could add another $\$ 500$ or more to the total cost of attending conferences. By contrast, the Consumer Price Index, one of the federal government's principal ways of calculating inflation, experienced an increase of a factor of five between 1971 and 2005. Thus, the real costs of attending a conference have increased by a factor of 2.6 over this period.

IMPLICATIONS OF RISING COSTS. It should come as no surprise that these rapid increases in costs to attend conferences have a potentially deleterious effect upon meetings. The high costs of travel have caused Congress to apply limits to the amount of travel at the Department of Commerce, hitting National Weather Service (NWS) employees especially hard. Between 1999 and 2006, attendance at the AMS Annual Meeting by government employees has dropped (Figs. 5a,b). A similar trend can be seen for first-authored presentations by NWS employees at the Radar Conference between 1997 and 2005 (Fig. 1 in the Geerts et al. article in the August 2006 Bulletin). A similar downward trend is seen in Fig. $5 b$ in the student attendance percentage, despite the number of university employees nearly doubling over the same period, as seen in Fig. 5a (i.e., faculty and staff at universities are less likely to take students with them to the AMS Annual Meeting, despite the increase in activities for students in the last few years).

University faculty who are principal investigators (PIs) fortunate enough to have funded research grants often operate on a fixed budget for the duration of the grant (typically three years for National Science Foundation grants). As an example, the grants under the NWS Collaborative Science, Technology, and Applied Research Program (CSTAR) program, which has supported university PIs and their students across the country from 2001 to 2006 , remained level at a maximum of $\$ 125,000$ per year. Level funding squeezes the number of research-related trips PIs can take and the number of students they can afford to bring to conferences, given the rapidly rising costs. While the AMS can pass increasing costs down to its members, PIs have less flexibility to adjust to these rapidly escalating costs when they operate on fixed budgets for threeyear periods and/or when the trend is toward more 
TABLE I. Income and expenses for a typical specialty conference.

\begin{tabular}{|c|c|c|c|}
\hline GROSS INCOME & $\begin{array}{l}\text { TOTAL } \\
\text { AMOUNT }\end{array}$ & $\begin{array}{l}\text { AMOUNT PER } \\
\text { ATTENDEE } \\
\text { (250 ATTENDEES) }\end{array}$ & NOTES \\
\hline $\begin{array}{c}\text { Abstract Fees \& Page } \\
\text { Charges }\end{array}$ & $\$ 33,750$ & $\$ 135$ & \\
\hline Registration Fees & $\$ 88,750$ & $\$ 355$ & \\
\hline $\begin{array}{l}\text { Adjustment for Credit } \\
\text { Cards }\end{array}$ & $-\$ 2000$ & $-\$ 8$ & $\begin{array}{l}\text { Cost of accepting credit cards as payment and lost } \\
\text { income due to uncollected purchase orders }\end{array}$ \\
\hline A. AVAILABLE INCOME & $\$ 120,500$ & $\$ 482$ & \\
\hline \multicolumn{4}{|l|}{ EXPENSES } \\
\hline Meeting Staff Salaries & $\$ 15,000$ & $\$ 60$ & 6 full-time and I part-time staff \\
\hline Support Staff Salaries & $\$ 10,000$ & $\$ 40$ & Computer support, etc. \\
\hline Overhead Staff Salaries & $\$ 22,000$ & $\$ 88$ & Accounting, executive director, other staff, etc. \\
\hline Meeting Staff Travel & $\$ 2,400$ & $\$ 9.60$ & Airfare, lodging, and meals for 2 staff members \\
\hline Facility Rental & 0 & 0 & $\begin{array}{l}\text { For a typical budget, this is zero. However, it is site- } \\
\text { dependent based on the food and beverage and the } \\
\text { contracted sleeping room block. AMS must keep the } \\
\text { ratio of blocked sleeping rooms consistent with the } \\
\text { requested amount of meeting room space. }\end{array}$ \\
\hline Food \& Beverage & $\$ 23,750$ & $\$ 95$ & $\begin{array}{l}\text { Allocation per attendee: Opening Reception }-\$ 10 \text {; } \\
\text { Coffee for the week }-\$ 40 ; \text { Banquet }-\$ 45\end{array}$ \\
\hline $\begin{array}{l}\text { On-Site Expenses (audio/ } \\
\text { visual, supplies, } \\
\text { materials, etc.) }\end{array}$ & $\$ 10,000$ & $\$ 40$ & $\begin{array}{l}\text { Audio/visual needs, computers, and internet } \\
\text { connection }\end{array}$ \\
\hline CD, Online, Recordings & $\$ 12,500$ & $\$ 50$ & $\begin{array}{l}\text { Base fee per meeting- } \$ 4,250 ; C D-\$ 5,000 \\
\text { (includes } \$ 3000 \text { setup fee); Recording of pre- } \\
\text { sentations- } \$ 1,200 \text {; Conference Exchange Staff } \\
\text { Travel- } \$ 1,500\end{array}$ \\
\hline Program Chair Fund & $\$ 1,500$ & $\$ 6$ & $\begin{array}{l}\text { Discretionary money for program chair_often used } \\
\text { for Student Travel awards or Best Student Presenta- } \\
\text { tion awards }\end{array}$ \\
\hline Poster Session & $\$ 3,600$ & $\$ 14.40$ & $\$ 90$ per board, 80 posters, 2 sessions \\
\hline Overhead and G\&A & $\$ 18,000$ & $\$ 72$ & Calculated based on the estimated meeting size \\
\hline $\begin{array}{l}\text { Contingency (On-site, Food } \\
\text { and Beverage, Posters) }\end{array}$ & $\$ 1,000$ & $\$ 4$ & Unexpected expenses \\
\hline B. TOTAL EXPENSES & $\$ 119,750$ & $\$ 479$ & \\
\hline A-B. NET INCOME & $\$ 750$ & $\$ 3$ & \\
\hline
\end{tabular}




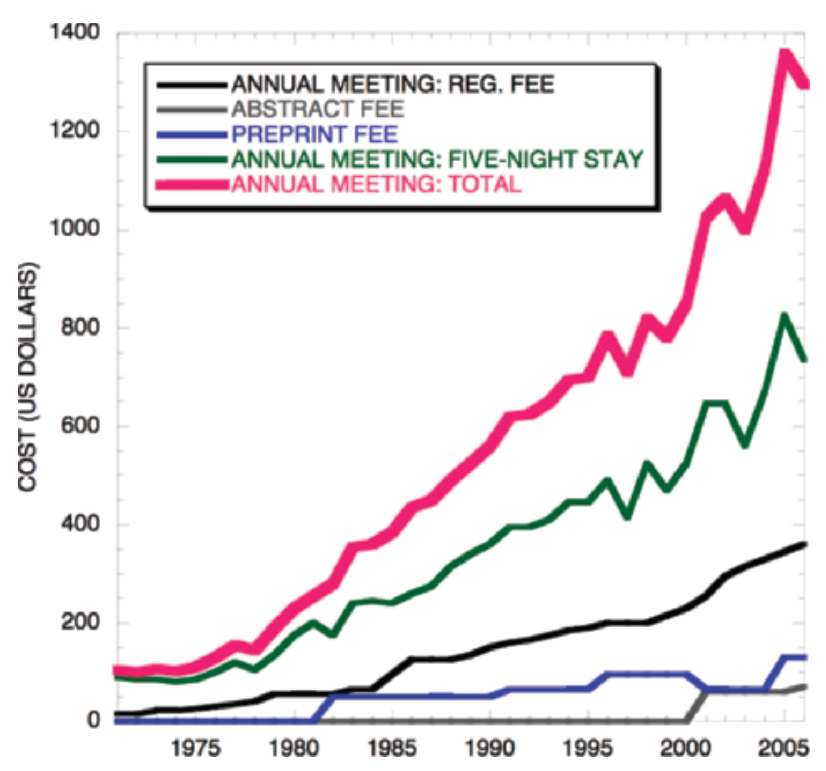

Fig. 4. The components of the total cost of attending the AMS Annual Meeting. Factors not included in this data include airfare, hotel taxes, per diem, and other expenses listed in the text. Preprint fees are estimated for many years because original data could not be found. For the preprint costs, note that for the early years shown on the graph, a I-2-page paper with no color is assumed to be included in a published preprint volume. For the later years, the fee provides for a preprint of perhaps many pages with full color to be included on a preprint CD-ROM and in the online database, and a recording of the presentation made available after the meeting.

level funding in specific dollar amounts (which can translate into declines in inflation-adjusted dollars), as appears to be the case today for many research grant-giving federal agencies.

The U.S. scientific enterprise is generously supported by the federal government. This support includes paying the direct cost of travel to AMS meetings and page charges for preprints and peerreviewed journal articles by government employees. It also includes indirect payment for similar travel and publications costs for nongovernment employees such as university researchers and their students out of research grants to individual principal investigators. The AMS is an indirect beneficiary of this support by the federal government for the scientific enterprise to the extent that it collects registration, abstract, and preprint fees from meeting participants, who in turn were supported by the federal government. Likewise, the AMS receives direct support from the federal government (National Science Foundation) for vari- ous outreach activities such as Project Datastreme. Without this federal government support, AMS conferences would be far less frequent and far smaller. Rapid growth in anything can only be sustained for so long before corrective forces emerge. Those of us who have been fortunate to receive direct or indirect support from the federal government for science-related activities, as well as those organizations such as the AMS that benefit from this support, need to recognize that the fiscal pie can be made only so big, and that we all have an obligation to explore alternative business models that have a chance to constrain rapidly rising costs while facilitating communication and the exchange of scientific ideas that are the hallmarks of face-to-face contact at scientific meetings.

As we saw a few years ago, declining attendance can create a spiral in which reduced revenue leads to higher registration fees to cover the fixed costs. Fortunately, meetings over the past year or two have done somewhat better in terms of attendance, and while hotel costs and airfares rise, there is some optimism that increases in registration fees can be contained. To see more specifically how this might be done, we look more closely at a budget for a typical specialty conference (e.g., Mesoscale Processes, Hurricanes and Tropical Meteorology Conference).

\section{BUDGET FOR A TYPICAL SPECIALTY}

MEETING. A representative budget for this type of meeting (Table 1) has been prepared by the meetings staff and provided to all committees of the Scientific and Technological Activities Commission (STAC) to help as they choose options for customizing future meetings. The budget numbers are based on actual expenses from meetings of similar size in the past year or two.

For the purposes of this exercise, assume the conference occurs in the spring (no seasonal impact) in the southern United States. Two-hundred and fifty people attend and 250 abstracts are submitted, half of which lead to preprints included online and on a CDROM. The conference is big enough that parallel sessions occur, and there are two poster sessions. There are no exhibits and no short courses. The meeting lasts $4-5$ days and has a standard banquet. For such a meeting, the base registration fee for AMS members is $\$ 360$. Accounting for one-day attendees, walk-up registration, and students, the average registration fee among the 250 attendees is $\$ 355$.

A meeting of this size represents about a $\$ 120,000$ event (Table 1). Attendees unfamiliar with hotel 
charges are frequently surprised at the high costs associated with items such as coffee or soft drinks during the breaks, which are frequently $\$ 2.50$ or more per serving. Experience shows that, on average, people tend to drink 1.5 cups of coffee per break. Adding tax and gratuity (set by the hotel at a standard rate), coffee costs $\$ 40$ per person per week, sometimes more depending on the location. The hotel contract typically requires the use of hotel services for food and beverages, and this guaranteed income is part of the reason that the meeting rooms themselves are typically offered by the hotel at no cost. The other main reason is the income that the hotel gains from the sleeping rooms used by the attendees. The negotiation process for securing a conference hotel is often a balancing act between the guaranteed minimum food and beverage expenditures, possible meeting room charges, and the number and rate of sleeping rooms booked at the hotel. In many contracts, failure to fill the minimum room block in the hotel can trigger very significant penalties, so care is taken to get the room rate as low as possible (hopefully with at least some portion of the block at the government per diem rate or lower), while still keeping costs associated with other services needed from the hotel as low as possible.

Salaries of AMS staff occupy a large fraction of the conference costs (39\%; see Table 1), a conclusion also reached by Charles Doswell III in 1999 (see "For Further Reading"). The salaries in the meetings portion of the AMS budget are allocated to a particular meeting based roughly on the expected size of that meeting at the time the budget is prepared. This number includes three types of salaries as a result of the way the AMS handles its accounting. First, there are the salaries of the six full-time and one parttime staff members devoted to meetings planning and operations. Next are support staff, who spend a portion of their time on meetings operations, such as computer support (including on-site support at the meetings). Their salary is apportioned to the meetings component of the AMS budget based on a simple allocation formula. Finally, a portion of overhead salaries is also allocated to the meetings based on a formula. The overhead salaries include personnel in the accounting department, the executive director and executive program support staff, and the staff that support the commissions and other volunteer components of the Society. The split of the $\$ 47,000$ salary value shown for this typical meeting works out to be approximately $\$ 15,000$ for meetings staff, $\$ 10,000$ for support staff, and $\$ 22,000$ for overhead salaries. (Note that these salary values include all fringe benefits.)

The overhead salary portion $(\$ 22,000$, or $18.3 \%$ of the total budget) of this $\$ 47,000$ is perhaps larger than some would expect. The AMS has a large array of programs and initiatives that support the community but that do not generate any revenue of their own, such as public information and student programs. In addition, the AMS has also increased its staff in the past decade or so to provide better in-house support to the various volunteer boards that carry out these programs and initiatives in the various boards and committees, as well as increased support for local chapters, the awards process, and other activities of

(a)

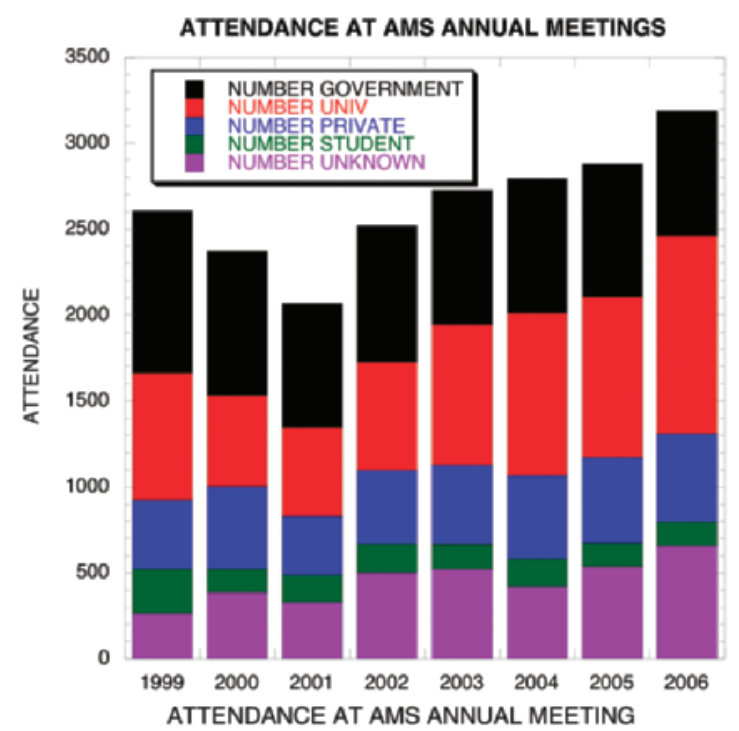

(b)

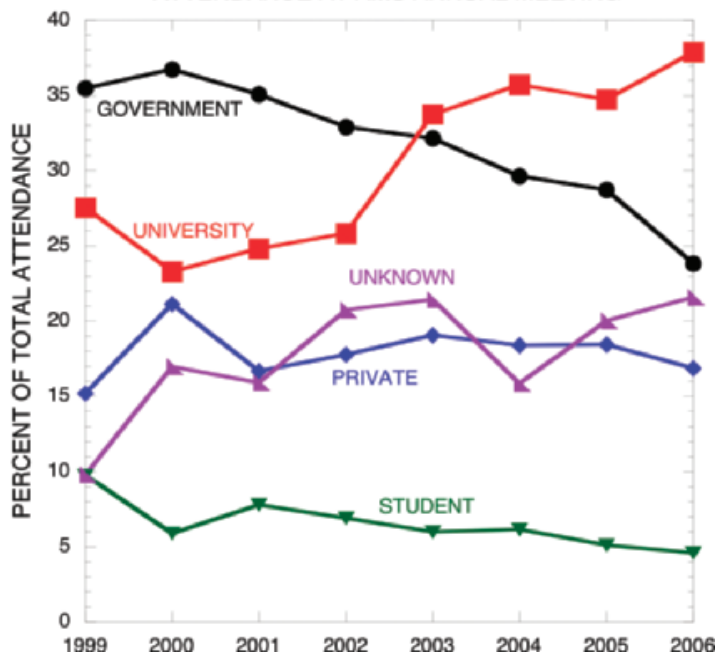

FIG. 5. Attendance at AMS Annual Meetings (1999-2006) by type of attendee: a) number, and b) percent. 
the Society. All of these staff salaries, in addition to the accounting office staff, etc., are paid from the overhead generated by the major budget categories (e.g., Member Services, Meetings, Publications). The Publications component of the AMS budget carries the largest portion of this overhead allocation because it is the largest portion of the budget, but the Bulletin portion of the budget (which includes Member Services) and the Meetings and Books components have overhead allocated to them as well. The Council recently approved a change in the way the overhead is allocated among the major budget areas in order to lessen the burden on the meetings portion of the budget as one way to help contain registration fees, but these expenses must still be covered in some other manner by the revenue-generating components of the total AMS budget.

The large percentage of the registration fees that go to staff salaries might lead some to question whether this cost has been responsible for the rapid increase in costs over the last 10 years. AMS budget data do not bear this out. In 1995, the AMS spent $\$ 602,256$ on staff salaries in the meetings budget. By 2005, this amount rose to $\$ 788,390$, approximately a $3 \%$ increase per year, the same as inflation. These numbers do not tell the full story, however. Over the years, more staff members have been working directly with the STAC committees, while they have been cutting back hours needed for other functions by taking advantage of newer technologies.

The line item in the budget labeled "Overhead and G\&A" (General and Administrative) includes the traditional overhead expenses, such as equipment, rent and utilities, and similar expenses. The G\&A portion includes the costs of supporting the AMS Council, legal fees, audit expenses, and a variety of other expenses that are grouped separately as dictated by nonprofit accounting practices. The meetings portion of the overall AMS budget carries a portion of the total AMS overhead and G\&A expense, and a portion of that is allocated to each meeting based on the meeting's anticipated size.

One way to further analyze this budget is to calculate a per-attendee value for income and expense. Assuming 250 attendees, about $\$ 188$ of each attendee's registration fees, abstract fees, and preprint page charges go toward staff salaries, about $\$ 95$ toward food and beverages, and about $\$ 40$ toward on-site expenses such as audio/visual support (e-mail stations, rental of hotel equipment, internet connectivity charges). Most of these per-attendee expenses are comparable to those published by SIAM, but in a few cases the AMS costs are higher.

Similar tables and calculations can be made for the AMS Annual Meeting. That meeting typically has total expenses of $\$ 1.6-\$ 1.7$ million, and a total paid attendance of between 2,500 and 3,000 (with typically about half of this number being authors), so the perattendee income is lower than for a specialty meeting (because there are fewer papers per attendee), while the per-attendee expenses are significantly higher (costs of \$530-680 per attendee). The Annual Meeting has a large exhibits program, however, that helps cover some of the major expenses, such as the rental fees associated with the convention center and other expenses that are not typically a part of a smaller specialty meeting.

There is some arbitrariness to the allocation of salaries, overhead, etc., to the specialty meetings compared to the Annual Meeting. With the currently used allocation, both the Annual Meeting and the aggregate of specialty meetings separately are close to break-even financially when the total meetings budget breaks even (as was the case in 2005), so we believe the current apportionment is at least reasonable.

OPTIONS FOR THE FUTURE. If the current trends were to continue, meetings would be so prohibitively costly that they would cease to be an effective approach for the dissemination of scientific results. For some, that point may have already been reached. The AMS Ten-Year Vision (www.ametsoc. org/EXEC/TenYear/IOyr_698.html) anticipated this to some extent, and recommended exploiting technology in new ways to provide additional options for useful scientific exchange. Posting preprints and the recorded presentations freely online are responses to the Ten-Year Vision recommendation to disseminate research results to those not able to attend the meeting. But, as previously discussed, although attendees may be deriving more benefits from the technology employed at meetings, these changes have increased the cost of meetings.

Compared to some professional societies that have conferences with catered meals, continental breakfasts, and receptions every night included in the registration fee, AMS meetings are relatively spartan affairs. Because other professional societies generate more income for the hotel, the AMS has 
greater difficulty negotiating with conference hotels. Coordinating with other professional societies to negotiate together using a professional national meeting planner (rather than AMS staff) might be one way to negotiate better rates with the hotels.

A point that is frequently raised in discussions of meetings costs is the potential use of less expensive university facilities. The AMS has had successful meetings at universities in the past, but it has become more difficult in recent years to pursue this option because universities now often have facility fees that are not competitive with the low or no-cost meeting room fees that can be negotiated with most hotels. While this option should never be dismissed, recent experience has indicated that it is difficult for this approach to lead to significant savings. Other facilities, such as the National Center for Atmospheric Research (NCAR), can and have been used for some AMS meetings, but typically not for a full conference-though that would be a possibility if the facility was willing to make the space available and other logistical aspects allowed the total finances to work out favorably.

A few program committees have experimented with lower-cost meetings through very careful venue selection, significant reductions in food and beverage, and minimal online dissemination. While such savings reduce registration fees, some feel these meetings are less effective in the long run because they offer fewer organized times for social interaction and a less complete record of the meeting for those who did not attend. Many program committees would like to expand the social interaction at meetings to enhance scientific exchange, with additional items such as buffet meals during poster viewing, etc., and point to the value of such increased collegial interactions. How to reconcile the desire to make a meeting more effective with the desire to make it less expensive is not clear. The program committee has some flexibility in these decisions, yet some committee members feel that they should have more control over setting meeting prices.

One of the ways that AMS members can help keep costs down is to stay in the recommended conference hotel. By meeting the obligation for filling a minimum number of rooms (and thus not encountering excessive penalties), the AMS can negotiate better rates in the future.

The AMS staff will continue to work hard to contain the cost increases while still trying to pro- vide meetings that satisfy the needs of the scientific community for productive interactions. We hope this analysis of the escalating expenses for AMS meetings will contribute to the ongoing dialogue on these issues taking place in the AMS Scientific and Technological Activities Commission, which oversees AMS meetings. The authors welcome feedback from the AMS membership on these topics.

That increases in registration fees and hotel costs are comparable to those being experienced by societies serving other disciplines provides little comfort, given the manifold increases that have occurred over the past three decades. The rate of increase threatens to jeopardize the viability of scientific conferences as an effective means of gathering the community for scientific exchange.

ACKNOWLEDGMENTS. Funding for Schultz was provided by NOAA/Office of Oceanic and Atmospheric Research under NOAA-University of Oklahoma Cooperative Agreement NA17RJ1227, U.S. Department of Commerce. An earlier draft of this manuscript was shared to members of the STAC Committees by STAC Commissioner Roger Wakimoto. Comments by Carrie Burleson, Charles Doswell III, John Knox, Jeffrey Lazo, Jeff Rosenfeld, and many members of the AMS STAC Committees have improved this manuscript.

\section{FOR FURTHER READING}

AMS, 2000: Abstract submission fee instituted and preprint page charges lowered for AMS meetings. Bull. Amer. Meteor. Soc., 81, 1612.

Crowley, J. M., 2000: Maximizing quality, minimizing cost-The optimization of a SIAM meeting. SIAM News, 33. [Available online at www.siam.org/news/ news.php?id=687.]

Doswell, C. A. III, 1999: An analysis of AMS meeting costs. Unpublished manuscript. [Available online at www.cimms.ou.edu/ doswell/AMS_meeting_costs. html.]

Geerts, B., S. E. Koch, P. Krehbiel, and D. Jorgensen, 2006: Are AMS conference practices changing for better or worse? A report on developments from the 32nd Radar Meteorology and 11th Mesoscale Processes Joint Conference. Bull. Amer. Meteor. Soc., 87, 1105-1110.

SIAM, 2005: Why aren't SIAM conferences cheaper? SIAM News, 38. [Available online at www.siam. org/news/news.php?id=24.] 